\title{
Tripled coincidence point theorems for weak $\phi$-contractions in partially ordered metric spaces
}

\author{
Hassen Aydi ${ }^{1 *}$, Erdal Karapinar ${ }^{2}$ and Mihai Postolache ${ }^{3}$
}

\author{
* Correspondence: hassen. \\ aydi@isima.rnu.tn \\ ${ }^{1}$ Institut Supérieur d'Informatique \\ et des Technologies de \\ Communication de Hammam \\ Sousse, Université de Sousse, Route \\ GP1-4011, Hammam Sousse, \\ Tunisie \\ Full list of author information is \\ available at the end of the article
}

\begin{abstract}
In this article, we present tripled coincidence point theorems for $F: X^{3} \rightarrow X$ and $g: X$ $\rightarrow X$ satisfying weak $\phi$-contractions in partially ordered metric spaces. We also provide nontrivial examples to illustrate our results and new concepts presented herein. Our results unify, generalize and complement various known comparable results from the current literature, Berinde and Borcut and Abbas et al.
\end{abstract}

\section{Introduction}

Fixed point theory has fascinated hundreds of researchers since 1922 with the celebrated Banach's fixed point theorem. This theorem provides a technique for solving a variety of applied problems in mathematical sciences and engineering. There exists a last literature on the topic and this is a very active field of research at present. There are great number of generalizations of the Banach contraction principle. Bhaskar and Lakshmikantham [1] introduced the notion of coupled fixed point and proved some coupled fixed point results under certain conditions, in a complete metric space endowed with a partial order. Later, Lakshmikantham and Ćirić [2] extended these results by defining the mixed $g$-monotone property. More accurately, they proved coupled coincidence and coupled common fixed point theorems for a mixed $g$-monotone mapping in a complete metric space endowed with a partial order. Karapinar $[3,4]$ generalized these results on a complete cone metric space endowed with a partial order. For other results on coupled fixed point theory, we address the readers to [5-13].

To make our exposition self contained, in this section we recall some previous notations and known results.

For simplicity, we denote from now on $\underbrace{X \times X \cdots X \times X}_{k \text { terms }}$ by $X^{k}$, where $k \in \mathbb{N}$ and $X$ be a non-empty set.

Let $(X, \leq)$ be a partially ordered set. According to [1], the mapping $F: X^{2} \rightarrow X$ is said to have mixed monotone property if $F(x, y)$ is monotone non-decreasing in $x$ and is monotone non-increasing in $y$, that is, for any $x, y \in X$,

$$
\begin{array}{ll}
x_{1} \leq x_{2} \Rightarrow F\left(x_{1}, y\right) \leq F\left(x_{2}, y\right), & \text { for } x_{1}, x_{2} \in X, \\
y_{1} \leq y_{2} \Rightarrow F\left(x, y_{2}\right) \leq F\left(x, y_{1}\right), & \text { for } y_{1}, y_{2} \in X .
\end{array}
$$


An element $(x, y) \in X^{2}$ is said to be a coupled fixed point of the mapping $F: X^{2} \rightarrow X$ if

$$
F(x, y)=x \text { and } \quad F(y, x)=y .
$$

Theorem 1.1. ([1]) Let $(X, \leq)$ be an ordered set such that there exists a metric $d$ on $X$ such that $(X, d)$ is complete. Let $F: X^{2} \rightarrow X$ be a continuous mapping having the mixed monotone property on $X$. Assume that there exists $k \in[0,1)$ with

$$
d(F(x, y), F(u, v)) \leq \frac{k}{2}[d(x, u)+d(y, v)], \text { for all } u \leq x, y \leq u .
$$

If there exist $x_{0}, y_{0} \in X$ such that $x_{0} \leq F\left(x_{0}, y_{0}\right)$ and $F\left(y_{0}, x_{0}\right) \leq y_{0}$, then, there exist $x$, $y\lfloor X$ such that $x=F(x, y)$ and $y=F(y, x)$.

Recently, Samet and Vetro [14] introduced the notion of fixed point of $\mathrm{N}$-order as natural extension of that of coupled fixed point and established some new coupled fixed point theorems in complete metric spaces, using a new concept of $F$-invariant set. Later, Berinde and Borcut [15] obtained existence and uniqueness of triple fixed point results in a complete metric space, endowed with a partial order.

Again, let $(X, \leq)$ be a partially ordered set. In accordance with [15], the mapping $F$ : $X^{3} \rightarrow X$ is said to have the mixed monotone property if for any $x, y, z \in X$

$$
\begin{aligned}
& x_{1}, x_{2} \in X, \quad x_{1} \leq x_{2} \Rightarrow F\left(x_{1}, y, z\right) \leq F\left(x_{2}, y, z\right), \\
& y_{1}, y_{2} \in X, \quad y_{1} \leq y_{2} \Rightarrow F\left(x, y_{1}, z\right) \geq F\left(x, y_{2}, z\right) \text {, } \\
& z_{1}, z_{2} \in X, \quad z_{1} \leq z_{2} \Rightarrow F\left(x, y, z_{1}\right) \leq F\left(x, y, z_{2}\right) \text {. }
\end{aligned}
$$

An element $(x, y, z) \in X^{3}$ is called a tripled fixed point of $F$ if

$$
F(x, y, z)=x, \quad F(y, x, y)=y \quad \text { and } \quad F(z, y, x)=z .
$$

Berinde and Borcut [15] proved the following theorem.

Theorem 1.2. ([15]) Let $(X, \leq)$ be a partially ordered set and $(X, d)$ be a complete metric space. Let $F: X^{3} \rightarrow X$ be a mapping having the mixed monotone property on $X$. Assume that there exist constants $a, b, c \in[0,1)$ such that $a+b+c<1$ for which

$$
d(F(x, y, z), F(u, v, w)) \leq a d(x, u)+b d(y, v)+c d(z, w)
$$

for all $x \geq u, y \leq v, z \geq w$. Assume either

(I) $F$ is continuous, or

(II) $X$ has the following properties:

(i) if non-decreasing sequence $x_{n} \rightarrow x$, then $x_{n} \leq x$ for all $n$,

(ii) if non-increasing sequence $y_{n} \rightarrow y$, then $y_{n} \geq y$ for all $n$.

If there exist $x_{0}, y_{0}, z_{0} \in X$ such that

$$
x_{0} \leq F\left(x_{0}, y_{0}, z_{0}\right), \quad y_{0} \geq F\left(y_{0}, x_{0}, y_{0}\right), \quad \text { and } z_{0} \leq F\left(x_{0}, y_{0}, z_{0}\right)
$$

then there exist $x, y, z \in X$ such that

$$
F(x, y, z)=x, F(y, x, y)=y, \quad \text { and } F(z, y, x)=z .
$$


In this article, we establish tripled coincidence point theorems for $F: X^{3} \rightarrow X$ and $g$ : $X \rightarrow X$ satisfying nonlinear contractive conditions, in partially ordered metric spaces. The presented theorems extend and improve some results in litterature.

\section{Main results}

We shall start this section by recalling the following basic notions, introduced by [Abbas, Aydi and Karapınar, Tripled common fixed point in partially ordered metric spaces, submitted]. In this respect, let us consider $(X, \leq)$ a partially ordered set, $F: X^{3}$ $\rightarrow X$ and $g: X \rightarrow X$ two mappings. The mapping $F$ is said to have the mixed $g$-monotone property if for any $x, y, z \in X$

$$
\begin{array}{ll}
x_{1}, x_{2} \in X, & g x_{1} \leq g x_{2} \Rightarrow F\left(x_{1}, y, z\right) \leq F\left(x_{2}, y, z\right), \\
y_{1}, y_{2} \in X, & g y_{1} \leq g y_{2} \Rightarrow F\left(x, y_{1}, z\right) \geq F\left(x, y_{2}, z\right), \\
z_{1}, z_{2} \in X, & g z_{1} \leq g z_{2} \Rightarrow F\left(x, y, z_{1}\right) \leq F\left(x, y, z_{2}\right) .
\end{array}
$$

An element $(x, y, z)$ is called a tripled coincidence point of $F$ and $g$ if

$$
F(x, y, z)=g x, \quad F(y, x, y)=g y, \quad \text { and } \quad F(z, y, x)=g z,
$$

while $(g x, g y, g z)$ is said a tripled point of coincidence of mappings $F$ and $g$. Moreover, $(x, y, z)$ is called a tripled common fixed point of $F$ and $g$ if

$$
F(x, y, z)=g x=x, \quad F(y, x, y)=g y=y, \quad \text { and } \quad F(z, y, x)=g z=z .
$$

At last, mappings $F$ and $g$ are called commutative if

$$
g(F(x, y, z))=F(g x, g y, g z), \quad \forall x, y, z \in X .
$$

In the same paper, they proved the following result.

Theorem 2.1. Let $(X, \leq)$ be a partially ordered set and suppose there is a metric $d$ on $X$ such that $(X, d)$ is a complete metric space. Assume there is a function $\phi:[0,+\infty) \rightarrow$ $[0,+\infty)$ such that $\phi(t)<t$ for each $t>0$. Also suppose $F: X^{3} \rightarrow X$ and $g: X \rightarrow X$ are such that $F$ has the mixed $g$-monotone property and suppose there exist $p, q, r \in[0,1)$ with $p+2 q+r<1$ such that

$$
d(F(x, y, z), F(u, v, w)) \leq \varphi(p d(g x, g u)+q d(g y, g v)+r d(g z, g w)),
$$

for any $x, y, z \in X$ for which $g x>g u, g v \geq g y$ and $g z \geq g w$.

Suppose $F\left(X^{3}\right) \subset g(X), g$ is continuous and commutes with F. Suppose either

(a) $F$ is continuous, or

(b) $X$ has the following properties:

(i) if non-decreasing sequence $g x_{n} \rightarrow x$ (respectively, $g z_{n} \rightarrow z$ ), then $g x_{n} \leq x$ (respectively, $g z_{n} \leq z$ ) for all $n$,

(ii) if non-increasing sequence $g y_{n} \rightarrow y$, then gy $y_{n} \geq y$ for all $n$.

If there exist $x_{0}, y_{0}, z_{0} \in X$ such that $g x_{0} \leq F\left(x_{0}, y_{0}, z_{0}\right), g y_{0} \geq F\left(y_{0}, x_{0}, y_{0}\right)$ and $g z_{0} \leq F$ $\left(z_{0}, y_{0}, x_{0}\right)$, then there exist $x, y, z \in X$ such that

$$
F(x, y, z)=g x, \quad F(y, x, y)=g y, \quad \text { and } F(z, y, x)=g z,
$$

that is, $F$ and $g$ have a tripled coincidence point. 
Before starting to introduce our results, let us consider the set of functions

$$
\Phi=\left\{\varphi:[0,+\infty) \rightarrow[0,+\infty) \mid \varphi(t)<t \text { and } \lim _{r \rightarrow t^{+}} \varphi(r)<t, \quad t>0\right\} .
$$

Our first main result is the following:

Theorem 2.2. Let $(X, \leq)$ be a partially ordered set and suppose there is a metric $d$ on $X$ such that $(X, d)$ is a complete metric space. Suppose $F: X^{3} \rightarrow X$ and $g: X \rightarrow X$ are such that $F$ has the mixed $g$-monotone property and $F\left(X^{3}\right) \subset g(X)$. Assume there is a function $\phi \in \Phi$ such that

$$
\begin{array}{r}
d(F(x, y, z), F(u, v, w))+d(F(y, x, y), F(v, u, v))+d(F(z, y, x), F(w, v, u)) \\
\leq 3 \varphi\left(\frac{d(g x, g u)+d(g y, g v)+d(g z, g w)}{3}\right),
\end{array}
$$

for any $x, y, z, u, v, w \in X$ for which $g x \geq g u, g v \geq g y$ and $g z \geq g w$. Assume that $F$ is continuous, $g$ is continuous and commutes with $F$. If there exist $x_{0}, y_{0}, z_{0} \in X$ such that

$$
g x_{0} \leq F\left(x_{0}, y_{0}, z_{0}\right), \quad g y_{0} \geq F\left(y_{0}, x_{0}, y_{0}\right) \quad \text { and } \quad g z_{0} \leq F\left(z_{0}, y_{0}, x_{0}\right),
$$

then there exist $x, y, z \in X$ such that

$$
F(x, y, z)=g x, \quad F(y, x, y)=g y, \quad \text { and } F(z, y, x)=g z,
$$

that is, $F$ and $g$ have a tripled coincidence point.

Proof. Let $x_{0}, y_{0}, z_{0} \in X$ be such that $g x_{0} \leq F\left(x_{0}, y_{0}, z_{0}\right), g y_{0} \geq F\left(y_{0}, x_{0}, y_{0}\right)$ and $g z_{0} \leq F$ $\left(z_{0}, y_{0}, x_{0}\right)$. We can choose $x_{1}, y_{1}, z_{1} \in X$ such that

$$
g x_{1}=F\left(x_{0}, y_{0}, z_{0}\right), \quad g y_{1}=F\left(y_{0}, x_{0}, y_{0}\right) \quad \text { and } \quad g z_{1}=F\left(z_{0}, y_{0}, x_{0}\right) .
$$

This can be done because $F\left(X^{3}\right) \subset g(X)$. Continuing this process, we construct sequences $\left\{x_{n}\right\},\left\{y_{n}\right\}$, and $\left\{z_{n}\right\}$ in $X$ such that

$$
g x_{n+1}=F\left(x_{n}, y_{n}, z_{n}\right), \quad g y_{n+1}=F\left(y_{n}, x_{n}, z_{n}\right), \quad \text { and } \quad g z_{n+1}=F\left(z_{n}, y_{n}, x_{n}\right) .
$$

By induction, we will prove that

$$
g x_{n} \leq g x_{n+1}, \quad g y_{n+1} \leq g y_{n}, \quad \text { and } g z_{n} \leq g z_{n+1} .
$$

Since $g x_{0} \leq F\left(x_{0}, y_{0}, z_{0}\right), g y_{0} \geq F\left(y_{0}, x_{0}, y_{0}\right)$, and $g z_{0} \leq F\left(z_{0}, y_{0}, x_{0}\right)$, therefore by (2.4) we have

$$
g x_{0} \leq g x_{1}, \quad g y_{1} \leq g y_{0}, \quad \text { and } g z_{0} \leq g z_{1} .
$$

Thus (2.6) is true for $n=0$. We suppose that (2.6) is true for some $n>0$. Since $F$ has the mixed $g$-monotone property, by $g x_{n} \leq g x_{n+1}, g y_{n+1} \leq g y_{n}$, and $g z_{n} \leq g z_{n+1}$, we have that

$$
\begin{aligned}
g x_{n+1}=F\left(x_{n}, y_{n}, z_{n}\right) & \leq F\left(x_{n+1}, y_{n}, z_{n}\right) \\
& \leq F\left(x_{n+1}, y_{n}, z_{n+1}\right) \\
& \leq F\left(x_{n+1}, y_{n+1}, z_{n+1}\right)=g x_{n+2}
\end{aligned}
$$




$$
\begin{aligned}
g y_{n+2}=F\left(y_{n+1}, x_{n+1}, y_{n+1}\right) & \leq F\left(y_{n+1}, x_{n}, y_{n+1}\right) \\
& \leq F\left(y_{n}, x_{n}, y_{n+1}\right) \\
& \leq F\left(y_{n}, x_{n}, y_{n}\right)=g y_{n+1},
\end{aligned}
$$

and

$$
\begin{aligned}
g z_{n+1}=F\left(z_{n}, y_{n}, x_{n}\right) & \leq F\left(z_{n+1}, y_{n}, x_{n}\right) \\
& \leq F\left(z_{n+1}, y_{n+1}, x_{n}\right) \\
& \leq F\left(z_{n+1}, y_{n+1}, x_{n+1}\right)=g z_{n+2} .
\end{aligned}
$$

That is, (2.6) is true for any $n \in \mathbb{N}$. If for some $k \in \mathbb{N}$

$$
g x_{k}=g x_{k+1}, \quad g y_{k}=g y_{k+1}, \quad \text { and } \quad g z_{k}=g z_{k+1},
$$

then, by (2.5), $\left(x_{k}, y_{k}, z_{k}\right)$ is a tripled coincidence point of $F$ and $g$. From now on, we assume that at least

$$
g x_{n} \neq g x_{n+1} \quad \text { or } \quad g y_{n} \neq g y_{n+1} \quad \text { or } \quad g z_{n} \neq g z_{n+1}
$$

for any $n \in \mathbb{N}$. From (2.6) and the inequality (2.2)

$$
\begin{aligned}
& d\left(g x_{n+1}, g x_{n}\right)+d\left(g y_{n+1}, g y_{n}\right)+d\left(g z_{n+1}, g z_{n}\right) \\
& \quad=d\left(F\left(x_{n}, y_{n}, z_{n}\right), F\left(x_{n-1}, y_{n-1}, z_{n-1}\right)\right)+d\left(F\left(y_{n}, x_{n}, y_{n}\right), F\left(y_{n-1}, x_{n-1}, y_{n-1}\right)\right) \\
& \quad+d\left(F\left(z_{n}, y_{n}, x_{n}\right), F\left(z_{n-1}, y_{n-1}, x_{n-1}\right)\right) \\
& \quad \leq 3 \varphi\left(\frac{1}{3}\left(d\left(g x_{n}, g x_{n-1}\right)+d\left(g y_{n}, g y_{n-1}\right)+d\left(g z_{n}, g z_{n-1}\right)\right) .\right.
\end{aligned}
$$

For each $n \geq 1$, take

$$
\delta_{n}:=\frac{1}{3}\left(d\left(g x_{n}, g x_{n-1}\right)+d\left(g y_{n}, g y_{n-1}\right)+d\left(g z_{n}, g z_{n-1}\right)\right) .
$$

One can write

$$
\delta_{n+1} \leq \varphi\left(\delta_{n}\right) \quad \forall n \geq 1 .
$$

By (2.7), we have $\delta_{n}>0$. Having in mind $\phi(t)<t$ for each $t>0$, so we have $\phi\left(\delta_{n}\right)<\delta_{n}$. From (2.9), we get

$$
\delta_{n+1}<\delta_{n} \quad \forall n \geq 1,
$$

that is, the sequence $\left\{\delta_{n}\right\}$ is non-negative and decreasing. Therefore, there exists some $\delta \geq 0$ such that

$$
\lim _{n \rightarrow+\infty} \delta_{n}=\lim _{n \rightarrow+\infty} \frac{1}{3}\left(d\left(g x_{n}, g x_{n-1}\right)+d\left(g y_{n}, g y_{n-1}\right)+d\left(g z_{n}, g z_{n-1}\right)\right)=\delta^{+} .
$$

We shall prove that $\delta=0$. Assume, on the contrary, that $\delta>0$. Then by letting $n \rightarrow$ $+\infty$ in (2.9) we have

$$
0<\delta=\lim _{n \rightarrow+\infty} \delta_{n+1} \leq \lim _{n \rightarrow+\infty} \varphi\left(\delta_{n}\right)=\lim _{r \rightarrow \delta^{+}} \delta(r)<\delta,
$$

which is a contradiction. Thus, $\delta=0$, and by (2.10), we get

$$
\lim _{n \rightarrow+\infty} \delta_{n}=0
$$


We now prove that $\left\{g x_{n}\right\}$, $\left\{g y_{n}\right\}$, and $\left\{g z_{n}\right\}$ are Cauchy sequences in $(X, d)$.

Suppose, on the contrary, that at least one of $\left\{g x_{n}\right\},\left\{g y_{n}\right\}$, and $\left\{g z_{n}\right\}$ is not a Cauchy sequence. So, there exists $\varepsilon>0$ for which we can find subsequences $\left\{g x_{n(\mathrm{k})}\right\},\left\{g x_{m(\mathrm{k})}\right\}$ of $\left\{g x_{n}\right\},\left\{g y_{n(k)}\right\},\left\{g y_{m(k)}\right\}$ of $\left\{g y_{n}\right\}$, and $\left\{g z_{n(k)}\right\},\left\{g z_{m(k)}\right\}$ of $\left\{g z_{n}\right\}$ with $n(k)>m(k) \geq k$ such that

$$
d\left(g x_{n(k)}, g x_{m(k)}\right)+d\left(g y_{n(k)}, g y_{m(k)}\right)+d\left(g z_{n(k)}, g z_{m(k)}\right) \geq \varepsilon .
$$

Additionally, corresponding to $m(k)$, we may choose $n(k)$ such that it is the smallest integer satisfying (2.12) and $n(k)>m(k) \geq k$. Thus,

$$
d\left(g x_{n(x)-1}, g x_{m(k)}\right)+d\left(g y_{n(k)-1}, g y_{m(k)}\right)+d\left(d z_{n(k)-1}, g z_{m(k)}\right)<\varepsilon .
$$

By using triangle inequality and having in mind (2.12) and (2.13)

$$
\begin{aligned}
\varepsilon \leq & t_{k}=d\left(g x_{n(k)}, g x_{m(k)}\right)+d\left(g y_{n(k)}, g y_{m(k)}\right)+d\left(g z_{n(k)}, g z_{m(k)}\right) \\
\leq & d\left(g x_{n(k)}, g x_{n(k)-1}\right)+d\left(g x_{n(k)-1}, g x_{m(k)}\right)+d\left(g y_{n(k)}, g y_{n(k)-1}\right) \\
& +d\left(g y_{n(k)-1}, g y_{m(k)}\right)+d\left(g z_{n(k)}, g z_{n(k)-1}\right)+d\left(g z_{n(k)-1}, g z_{m(k)}\right) \\
< & d\left(g x_{n(k)}, g x_{n(k)-1}\right)+d\left(g y_{n(k)}, g y_{n(k)-1}\right)+d\left(g z_{n(k)}, g z_{n(k)-1}\right)+\varepsilon .
\end{aligned}
$$

Letting $k \rightarrow \infty$ in (2.14) and using (2.11)

$$
\lim _{k \rightarrow \infty} t_{k}=\lim _{k \rightarrow \infty} d\left(g x_{n(k)}, g x_{m(k)}\right)+d\left(g y_{n(k)}, g y_{m(k)}\right)+d\left(g z_{n(k)}, g z_{m(k)}\right)=\varepsilon .
$$

Again by triangle inequality,

$$
\begin{aligned}
t_{k}= & d\left(g x_{n(k)}, g x_{m(k)}\right)+d\left(g y_{n(k)}, g y_{m(k)}\right)+d\left(g z_{n(k)}, g z_{m(k)}\right) \\
\leq & d\left(g x_{n(k)}, g x_{n(k)+1}\right)+d\left(g x_{n(k)+1}, g x_{m(k)+1}\right)+d\left(g x_{m(k)+1}, g x_{m(k)}\right) \\
& +d\left(g y_{n(k)}, g y_{n(k)+1}\right)+d\left(g y_{n(k)+1}, g y_{m(k)+1}\right)+d\left(g y_{m(k)+1}, g y_{m(k)}\right) \\
& +d\left(g z_{n(k)}, g z_{n(k)+1}\right)+d\left(g z_{n(k)+1}, g y_{m(k)+1}\right)+d\left(g z_{m(k)+1}, g z_{m(k)}\right) \\
\leq & \delta_{n(k)+1}+\delta_{m(k)+1}+d\left(g x_{n(k)+1}, g x_{m(k)+1}\right)+d\left(g y_{n(k)+1}, g y_{m(k)+1}\right) \\
& +d\left(g z_{n(k)+1}, g z_{m(k)+1}\right) .
\end{aligned}
$$

Since $n(k)>m(k)$, then

$$
g x_{n(k)} \geq g x_{m(k)}, \quad g y_{n(k)} \leq g y_{m(k)}, \quad g z_{n(k)} \geq g z_{m(k)} .
$$

Take (2.17) in (2.2) to get

$$
\begin{aligned}
& d\left(g x_{n(k)+1}, g x_{m(k)+1}\right)+d\left(g y_{n(k)+1}, g y_{m(k)+1}\right)+d\left(g z_{n(k)+1}, g z_{m(k)+1}\right) \\
& \quad=d\left(F\left(x_{n(k)}, y_{n(k)}, z_{n(k)}\right), F\left(x_{m(k)}, y_{m(k)}, z_{m(k)}\right)\right. \\
& \quad+d\left(F\left(y_{n(k)}, x_{n(k)}, y_{n(k)}\right), F\left(y_{m(k)}, x_{m(k)}, y_{m(k)}\right)\right. \\
& \quad+d\left(F\left(z_{n(k)}, y_{n(k)}, x_{n(k)}\right), F\left(z_{m(k)}, y_{m(k)}, x_{m(k)}\right)\right) \\
& \quad \leq 3 \varphi\left(\frac{1}{3}\left[d\left(g x_{n(k)}, g x_{m(k)}\right)+d\left(g y_{n(k)}, g y_{m(k)}\right)+d\left(g z_{n(k)}, g z_{m(k)}\right)\right]\right) \\
& \quad=3 \varphi\left(\frac{t_{k}}{3}\right) .
\end{aligned}
$$


Combining this in (2.16), we obtain that

$$
\begin{aligned}
t_{k} \leq & \delta_{n(k)+1}+\delta_{m(k)+1}+d\left(g x_{n(k)+1}, g x_{m(k)+1}\right)+d\left(g y_{n(k)+1}, g y_{m(k)+1}\right) \\
& +d\left(g z_{n(k)+1}, g z_{m(k)+1}\right) \\
\leq & \delta_{n(k)+1}+\delta_{m(k)+1}+3 \varphi\left(\frac{t_{k}}{3}\right) .
\end{aligned}
$$

Letting $k \rightarrow \infty$ and having in mind (2.11) and (2.15), we get

$$
\varepsilon \leq 3 \lim _{k \rightarrow+\infty} \varphi\left(\frac{1}{3} t_{k}\right)=3 \lim _{r \rightarrow\left(\frac{1}{3} t\right)_{+}} \phi(r)<3\left(\frac{1}{3} \varepsilon\right)=\varepsilon
$$

which is a contradiction. This shows that $\left\{g x_{n}\right\},\left\{g y_{n}\right\}$, and $\left\{g z_{n}\right\}$ are Cauchy sequences in $(\mathrm{X}, d)$.

Since $X$ is complete, there exist $x, y, z \in X$ such that

$$
\lim _{n \rightarrow+\infty} g x_{n}=x, \quad \lim _{n \rightarrow+\infty} g y_{n}=y \text { and } \lim _{n \rightarrow+\infty} g z_{n}=z .
$$

From (2.18) and the continuity of $g$.

$$
\lim _{n \rightarrow+\infty} g\left(g x_{n}\right)=g x, \quad \lim _{n \rightarrow+\infty} g\left(g y_{n}\right)=g y, \text { and } \lim _{n \rightarrow+\infty} g\left(g z_{n}\right)=g z .
$$

From the commutativity of $F$ and $g$, we have

$$
\begin{aligned}
& g\left(g x_{n+1}\right)=g\left(F\left(x_{n}, y_{n}, z_{n}\right)\right)=F\left(g x_{n}, g y_{n}, g z_{n}\right), \\
& g\left(g y_{n+1}\right)=g\left(F\left(y_{n}, x_{n}, y_{n}\right)\right)=F\left(g y_{n}, g x_{n}, g y_{n}\right), \\
& g\left(g z_{n+1}\right)=g\left(F\left(z_{n}, y_{n}, x_{n}\right)\right)=F\left(g z_{n}, g y_{n}, g x_{n}\right) .
\end{aligned}
$$

Now we shall show that $g x=F(x, y, z), g y=F(y, x, y)$, and $g z=F(z, y, x)$.

Suppose that $F$ is continuous. Letting $n \rightarrow+\infty$ in (2.20), therefore by (2.18) and (2.19), we obtain

$$
\begin{aligned}
g x=\lim _{n \rightarrow+\infty} g\left(g x_{n+1}\right) & =\lim _{n \rightarrow+\infty} F\left(g x_{n}, g y_{n}, g z_{n}\right) \\
& =F\left(\lim _{n \rightarrow+\infty} g x_{n}, \lim _{n \rightarrow+\infty} g y_{n}, \lim _{n \rightarrow+\infty} g z_{n}\right)=F(x, y, z), \\
g y=\lim _{n \rightarrow+\infty} g\left(g y_{n+1}\right) & =\lim _{n \rightarrow+\infty} F\left(g y_{n}, g x_{n}, g y_{n}\right) \\
& =F\left(\lim _{n \rightarrow+\infty} g y_{n}, \lim _{n \rightarrow+\infty} g x_{n}, \lim _{n \rightarrow+\infty} g y_{n}\right)=F(y, x, y),
\end{aligned}
$$

and

$$
\begin{aligned}
g z=\lim _{n \rightarrow+\infty} g\left(g z_{n+1}\right) & =\lim _{n \rightarrow+\infty} F\left(g z_{n}, g y_{n}, g x_{n}\right) \\
& =F\left(\lim _{n \rightarrow+\infty} g z_{n}, \lim _{n \rightarrow+\infty} g y_{n}, \lim _{n \rightarrow+\infty} g x_{n}\right)=F(z, y, x) .
\end{aligned}
$$

We have proved that $F$ and $g$ have a tripled coincidence point.

Corollary 2.3. Let $(X, \leq)$ be a partially ordered set and suppose there is a metric $d$ on $X$ such that $(X, d)$ is a complete metric space. Suppose $F: X^{3} \rightarrow X$ and $g: X \rightarrow X$ are such that $F$ has the mixed $g$-monotone property and $F\left(X^{3}\right) \subset g(X)$. Assume there exists $\alpha \in[0,1)$ such that 


$$
\begin{aligned}
d(F(x, y, z), F(u, v, w)) & +d(F(y, x, y), F(v, u, v))+d(F(z, y, x), F(w, v, u)) \\
& \leq \alpha(d(g x, g u)+d(g y, g v)+d(g z, g w))
\end{aligned}
$$

for any $x, y, z, u, v, w \in X$ for which $g x \geq g u, g v \geq g y$, and $g z \geq g w$. Assume that $F$ is continuous, $g$ is continuous and commutes with $F$. If there exist $x_{0}, y_{0}, z_{0} \in X$ such that

$$
g x_{0} \leq F\left(x_{0}, y_{0}, z_{0}\right), g y_{0} \geq F\left(y_{0}, x_{0}, y_{0}\right), \text { and } g z_{0} \leq F\left(z_{0}, y_{0}, x_{0}\right),
$$

then there exist $x, y, z \in X$ such that

$$
F(x, y, z)=g x, \quad F(y, x, y)=g y, \text { and } F(z, y, x)=g z,
$$

that is, $F$ and $g$ have a tripled coincidence point.

Proof. It follows by taking $\phi(t)=\alpha t$ in Theorem 2.2.

In the following theorem, we omit the continuity hypothesis of $F$. We need the following definition.

Definition 2.1. Let $(X, \leq)$ be a partially ordered set and $d$ be a metric on $X$. We say that $(X, d, \leq)$ is regular if the following conditions hold:

(i) if a non-decreasing sequence $\left(x_{n}\right)$ is such that $x_{n} \rightarrow x$, then $x_{n} \leq x$ for all $n$,

(ii) if a non-increasing sequence $\left(y_{n}\right)$ is such that $y_{n} \rightarrow y$, then $y \leq y_{n}$ for all $n$.

Theorem 2.4. Let $(X, \leq)$ be a partially ordered set and $d$ be a metric on $X$ such that $(X, d, \leq)$ is regular. Suppose that there exist $\phi \in \Phi$ and mappings $F: X^{3} \rightarrow X$ and $g: X$ $\rightarrow X$ such that (2.2) holds for any $x, y, z, u, v, w \in X$ for which $g x \geq g u, g v \geq g y$ and $g z$ $\geq g w$. Suppose also that $(g(X), d)$ is complete, $F$ has the mixed $g$-monotone property and $F\left(X^{3}\right) \subset g(X)$. If there exist $x_{0}, y_{0}, z_{0} \in X$ such that $g x_{0} \leq F\left(x_{0}, y_{0}, z_{0}\right), g y_{0} \geq F\left(y_{0}, x_{0}, y_{0}\right)$, and $g z_{0} \leq F\left(z_{0}, y_{0}, x_{0}\right)$, then there exist $x, y, z \in X$ such that

$$
F(x, y, z)=g x, \quad F(y, x, y)=g y, \text { and } F(z, y, x)=g z,
$$

that is, F and $g$ have a tripled coincidence point.

Proof. Proceeding exactly as in Theorem 2.2, we have that $\left(g x_{n}\right),\left(g y_{n}\right)$, and $\left(g z_{n}\right)$ are Cauchy sequences in the complete metric space $(g(X), d)$. Then, there exist $x, y, z \in X$ such that $g x_{n} \rightarrow g x, g y_{n} \rightarrow g y$, and $g z_{n} \rightarrow g z$. Since $\left(g x_{n}\right)$ and $\left(g z_{n}\right)$ are non-decreasing and $\left(g y_{n}\right)$ is non-increasing, using the regularity of $(X, d, \leq)$, we have $g x_{n} \leq g x, g z_{n} \leq g z$, and $g y \leq g y_{n}$ for all $n \geq 0$. If $g x_{n}=g x, g y_{n}=g y$, and $g z_{n}=g z$ for some $n \geq 0$, then $g x=$ $g x_{n} \leq g x_{n+1} \leq g x=g x_{n}, g z=g z_{n} \leq g z_{n+1} \leq g z=g z_{n}$, and $g y \leq g y_{n+1} \leq g y_{n}=g y$, which implies that $g x_{n}=g x_{n+1}=F\left(x_{n}, y_{n}, z_{n}\right), g y_{n}=g y_{n+1}=F\left(y_{n}, x_{n}, y_{n}\right)$, and $g z_{n}=g z_{n+1}=F$ $\left(z_{n}, y_{n}, x_{n}\right)$, that is, $\left(x_{n}, y_{n}, z_{n}\right)$ is a tripled coincidence point of $F$ and $g$. Then, we suppose that $\left(g x_{n}, g y_{n}, g z_{n}\right) \neq(g x, g y, g z)$ for all $n \geq 0$. Using the triangle inequality, (2.2) and the property $\phi(t)<t$ for all $t>0$,

$$
\begin{aligned}
d(g x, F(x, y, z)) \\
\quad \leq d\left(g x, g x_{n+1}\right)+d\left(g x_{n+1}, F(x, y, z)\right) \\
\quad=d\left(g x, g x_{n+1}\right)+d\left(F(x, y, z), F\left(x_{n}, y_{n}, z_{n}\right)\right) \\
\quad \leq d\left(g x, g x_{n+1}\right)+3 \varphi\left(\frac{1}{3}\left[d\left(g x_{n}, g x\right)+d\left(g y_{n}, g y\right)+d\left(d z_{n}, g z\right)\right]\right) \\
\quad<d\left(g x, g x_{n+1}\right)+d\left(g x_{n}, g x\right)+d\left(g y_{n}, g y\right)+d\left(g z_{n}, g z\right) .
\end{aligned}
$$


Taking $n \rightarrow \infty$ in the above inequality we obtain that $d(g x, F(x, y, z))=0$, so $g x=F(x$, $y, z)$.

Analogously, we find that

$$
F(y, x, y)=g y, \quad F(z, y, x)=g z
$$

thus, we have proved that $F$ and $g$ have a tripled coincidence point.

Corollary 2.5. Let $(X, \leq)$ be a partially ordered set and suppose there is a metric $d$ on $X$ such that $(X, \leq, d)$ is regular. Suppose $F: X^{3} \rightarrow X$ and $g: X \rightarrow X$ are such that $F$ has the mixed g-monotone property and $F\left(X^{3}\right) \subset g(X)$. Assume there exists $\alpha \in[0,1)$ such that

$$
\begin{aligned}
d(F(x, y, z), F(u, v, w)) & +d(F(y, x, y), F(v, u, v))+d(F(z, y, x), F(w, v, u)) \\
& \leq \alpha(d(g x, g u)+d(g y, g v)+d(g z, g w)),
\end{aligned}
$$

for any $x, y, z, u, v, w \in X$ for which $g x \geq g u, g v \geq g y$, and $g z \geq g w$. Suppose also that $(g(X), d)$ is complete. If there exist $x_{0}, y_{0}, z_{0} \in X$ such that

$$
g x_{0} \leq F\left(x_{0}, y_{0}, z_{0}\right), \quad g y_{0} \geq F\left(y_{0}, x_{0}, y_{0}\right) \text { and } g z_{0} \leq F\left(z_{0}, y_{0}, x_{0}\right),
$$

then there exist $x, y, z \in X$ such that

$$
F(x, y, z)=g x, \quad F(y, x, y)=g y, \quad \text { and } \quad F(z, y, x)=g z,
$$

that is, $F$ and $g$ have a tripled coincidence point.

Proof. It follows by taking $\phi(t)=\alpha t$ in Theorem 2.4 .

Now, we shall prove the existence and the uniqueness of a tripled common fixed point theorem. For a product $X^{3}=X \times X \times X$ of a partial ordered set $(X, \leq)$, we define a partial ordering in the following way: For all $(x, y, z),(u, v, r) \in X^{3}$

$$
(x, y, z) \leq(u, v, r) \Leftrightarrow x \leq u, y \geq v \text { and } z \leq r .
$$

We say that $(x, y, z)$ and $(u, v, w)$ are comparable if

$$
(x, y, z) \leq(u, v, r) \quad \text { or } \quad(u, v, r) \leq(x, y, z) .
$$

Also, we say that $(x, y, z)$ is equal to $(u, v, r)$ if and only if $x=u, y=v$ and $z=r$.

Theorem 2.6. In addition to hypothesis of Theorem 2.2, suppose that for all $(x, y, z)$ and $(u, v, r)$ in $X^{3}$, there exists $(a, b, c)$ in $X^{3}$ such that $(F(a, b, c), F(b, a, b), F(c, b, a))$ is comparable to $(F(x, y, z), F(y, x, y), F(z, y, x))$ and $(F(u, v, r), F(v, u, v), F(r, v, u))$. Also, assume that $\phi$ is non-decreasing. Then, $F$ and $g$ have a unique tripled common fixed point $(x, y, z)$, that is

$$
x=g x=F(x, y, z), \quad y=g y=F(y, x, y), \quad \text { and } z=g z=F(z, y, x) .
$$

Proof. Due to Theorem 2.2, the set of tripled coincidence points of $F$ and $g$ is not empty. Assume now, that $(x, y, z)$ and $(u, v, r)$ are two tripled coincidence points of $F$ and $g$, that is,

$$
\begin{aligned}
& F(x, y, z)=g x, \quad F(y, x, y)=g y, \quad \text { and } F(z, y, x)=g z, \\
& F(u, v, r)=g u, \quad F(v, u, v)=g v, \quad \text { and } F(r, v, u)=g r .
\end{aligned}
$$

We shall show that $(g x, g y, g z)$ and $(g u, g v, g r)$ are equal. 
By assumption, there is $(a, b, c)$ in $X^{3}$ such that $(F(a, b, c), F(b, a, b), F(c, b, a))$ is comparable to $(F(x, y, z), F(y, x, y), F(z, y, x))$ and $(F(u, v, r), F(v, u, v), F(r, v, u))$.

Define the sequences $\left\{g a_{n}\right\},\left\{g b_{n}\right\}$, and $\left\{g c_{n}\right\}$ such that $a=a_{0}, b=b_{0}, c=c_{0}$ and

$$
g a_{n}=F\left(a_{n-1}, b_{n-1}, c_{n-1}\right), g b_{n}=F\left(b_{n-1}, a_{n-1}, b_{n-1}\right), g c_{n}=F\left(c_{n-1}, b_{n-1}, a_{n-1}\right),
$$

for all $n$. Further, set $x_{0}=x, y_{0}=y, z_{0}=z$ and $u_{0}=u, v_{0}=v, r_{0}=r$, and similar define the sequences $\left\{g x_{n}\right\},\left\{g y_{n}\right\},\left\{g z_{n}\right\}$ and $\left\{g u_{n}\right\},\left\{g v_{n}\right\},\left\{g r_{n}\right\}$. Then,

$$
\begin{aligned}
& g x_{n}=F(x, y, z), \quad g u_{n}=F(u, v, r), \\
& g y_{n}=F(y, x, y,), \quad g v_{n}=F(v, u, v), \\
& g z_{n}=F(z, y, x), \quad g r_{n}=F(r, v, u,)
\end{aligned}
$$

for all $n \geq 1$. Since $(F(x, y, z), F(y, x, y), F(z, y, x))=\left(g x_{1}, g y_{1}, g z_{1}\right)=(g x, g y, g z)$ is comparable to $(F(a, b, c), F(b, a, b), F(c, b, a))=\left(g a_{1}, g b_{1}, g c_{1}\right)$, then it is easy to show that $(g x, g y, g z) \geq\left(g a_{1}, g b_{1}, g c_{1}\right)$. Recursively, we get that

$$
(g x, g y, g z) \geq\left(g a_{n}, g b_{n}, g c_{n}\right) \quad \text { for all } n \geq 0 .
$$

By (2.24) and (2.2), we have

$$
\begin{aligned}
d\left(g x, g a_{n+1}\right) & +d\left(g b_{n+1}, g y\right)+d\left(g z, g c_{n+1}\right)=d\left(F(x, y, z), F\left(a_{n}, b_{n}, c_{n}\right)\right) \\
& +d\left(F\left(b_{n}, a_{n}, b_{n}\right), F(y, x, y)\right)+d\left(F(z, y, x), F\left(c_{n}, b_{n}, a_{n}\right)\right. \\
& \leq 3 \varphi\left(\frac{d\left(g x, g a_{n}\right)+d\left(g y, g b_{n}\right)+d\left(g z, g c_{n}\right)}{3}\right) .
\end{aligned}
$$

Set

$$
\gamma_{n}=\frac{d\left(g x, g a_{n}\right)+d\left(g y, g b_{n}\right)+d\left(g z, g c_{n}\right)}{3}
$$

From (2.25), we deduce that $\gamma_{n+1} \leq \phi\left(\gamma_{n}\right)$. Since $\phi$ is non-decreasing, it follows

$$
\gamma_{n} \leq \varphi^{n}\left(\gamma_{0}\right)
$$

From the definition of $\Phi$, we get $\lim _{n \rightarrow+\infty} \varphi^{n}(t)=0$. Then, we have $\lim _{n \rightarrow+\infty} \gamma_{n}=0$. Thus,

$$
\lim _{n \rightarrow \infty} d\left(g x, g a_{n}\right)=0, \quad \lim _{n \rightarrow \infty} d\left(g y, g b_{n}\right)=0, \quad \lim _{n \rightarrow \infty} d\left(g z, g c_{n}\right)=0 .
$$

By analogy, we show that

$$
\lim _{n \rightarrow \infty} d\left(g u, g a_{n}\right)=0, \quad \lim _{n \rightarrow \infty} d\left(g v, g b_{n}\right)=0, \quad \lim _{n \rightarrow \infty} d\left(g r, g c_{n}\right)=0 .
$$

Combining (2.26) and (2.27) yields that ( $g x, g y, g z)$ and $(g u, g v, g r)$ are equal.

Since $g x=F(x, y, z), g y=F(y, x, y)$, and $g z=F(z, y, x)$, by the commutativity of $F$ and $g$, we have

$$
\begin{aligned}
& g(g x)=g(F(x, y, z))=F(g x, g y, g z), \\
& g(g y)=g(F(y, x, y))=F(g y, g x, g y), \\
& g(g z)=g(F(z, y, x))=F(g z, g y, g x) .
\end{aligned}
$$

Denote $g x=x^{\prime}, g y=y^{\prime}$, and $g z=z^{\prime}$. From the precedent identities,

$$
g x^{\prime}=F\left(x^{\prime}, y^{\prime}, z^{\prime}\right), \quad g y^{\prime}=F\left(y^{\prime}, x^{\prime}, y^{\prime}\right), \quad \text { and } g z^{\prime}=F\left(z^{\prime}, y^{\prime}, x^{\prime}\right),
$$


that is, $\left(x^{\prime}, y^{\prime}, z^{\prime}\right)$ is a tripled coincidence point of $F$ and $g$. Consequently, $\left(g x^{\prime}, g y^{\prime}, g z^{\prime}\right)$ and $(g x, g y, g z)$ are equal, that is, $g x=g x^{\prime}, g y=g y^{\prime}$, and $g z=g z^{\prime}$.

We deduce $g x^{\prime}=g x=x^{\prime}, g y^{\prime}=g y=y^{\prime}$, and $g z^{\prime}=g z=z^{\prime}$. Therefore, $\left(x^{\prime}, y^{\prime}, z^{\prime}\right)$ is a tripled common fixed of $F$ and $g$. Its uniqueness follows from Theorem 2.2.

\section{Examples}

Remark that Theorem 2.2 is more general than Theorem 2.1, since the contractive condition (2.2) is weaker than (2.1), a fact which is clearly illustrated by the following example.

Example 3.1. Let $X=\mathbb{R}$ with $d(x, y)=|x-y|$ and natural ordering and let $g: X \rightarrow X$, $F: X^{3} \rightarrow X$ be given by

$$
g(x)=\frac{n+1}{n} x, \quad n=1,2, \ldots, \quad x \in X ; \quad F(x, y, z)=x, \quad(x, y, z) \in X^{3} .
$$

It is clear that $F$ is continuous and has the mixed $g$-monotone property. We now take $\varphi(t)=\frac{n}{n+1} t$. We shall show that (2.2) holds for all $g x \geq g u, g y \leq g v$, and $g z \leq g w$.

Let $x, y, z, u, v$, and $w$ such that $g x \geq g u, g y \leq g v$, and $g z \leq g w$, and by definition of $g$, it means that $x \geq u, y \leq v$ and $z \leq w$, so we have

$$
\begin{aligned}
d(F(x, y, z), F(u, v, w)) & +d(F(y, x, y), F(v, u, v))+d(F(z, y, x), F(w, v, u)) \\
& =|x-u|+|y-v|+|z-w| \\
& =3 \varphi\left(\frac{d(g x, g u)+d(g y, g v)+d(g z, g w)}{3}\right) .
\end{aligned}
$$

which is the contractive condition (2.2). On the other hand, $x_{0}=0, y_{0}=0, z_{0}=0$ satisfy (2.3). All the hypotheses of Theorem 2.2 are verified, and $(0,0,0)$ is a tripled coincidence point of $F$ and $g$.

On the other hand, assume that (2.1) holds. Then, there exist $p, q, r \geq 0$ such that $p+$ $2 q+r<1$ and $\phi$ satisfying $\phi(t)<t$ for each $t>0$. If $x>u, z=w$ and $y=v$, we have

$$
\begin{aligned}
0<|x-u| & =d(F(x, y, z), F(u, v, w)) \\
& \leq \varphi(p d(g x, g u)+q d(g y, g v)+r d(g z, g w)) \\
& =\varphi\left(\frac{n+1}{n} p|x-u|\right)<\frac{n+1}{n} p|x-u|,
\end{aligned}
$$

which implies $p>\frac{n}{n+1}$ for any $n \geq 1$, and letting $n \rightarrow+\infty$, we get $p \geq 1$, that is a contradiction. Thus, Theorem 2.1 is not applicable in this case.

Following example shows that Theorem 2.2 is more general than Theorem 1.2.

Example 3.2. Let $X=\mathbb{R}$ be endowed with the usual ordering and the usual metric. Consider $g: X \rightarrow X$ and $F: X^{3} \rightarrow X$ be given by the formulas

$$
g(x)=x, \quad F(x, y, z)=\frac{3 x-6 y+3 z}{16}, \text { for all } x, y, z \in X
$$

Take $\phi:[0, \infty) \rightarrow[0, \infty)$ be given by $\varphi(t)=\frac{3 t}{4}$ for all $t \in[0, \infty)$.

It is clear that all conditions of Theorem 2.2 are satisfied. Moreover, $(0,0,0)$ is a tripled coincidence point (also a common fixed point) of $F$ and $g$. 
Now, for $x=u, z=w$ and $v>y$, we have

$$
d\left(F(x, y, z), F(u, v, w)=\frac{3}{8}(v-y)>\frac{1}{3}(v-y) \geq \frac{k}{3}[d(x, u)+d(y, v) d(z, w)]\right.
$$

for any $k \in[0,1)$, that is the result of Berinde and Borcut [15]given by Theorem 1.2 is not applicable (for $a=b=c=\frac{k}{3}$ ).

\section{Author details}

${ }^{1}$ Institut Supérieur d'Informatique et des Technologies de Communication de Hammam Sousse, Université de Sousse, Route GP1-4011, Hammam Sousse, Tunisie ²Department of Mathematics, Atılım University, Incek, Ankara 06836, Turkey ${ }^{3}$ University Politehnica of Bucharest, Faculty of Applies Sciences, 313 Splaiul Independenței, Romania

\section{Authors' contributions}

All authors contributed equally and significantly in writing this article. All authors read and approve the final manuscript.

\section{Competing interests}

The authors declare that they have no competing interests.

Received: 13 November 2011 Accepted: 21 March 2012 Published: 21 March 2012

\section{References}

1. Bhaskar, TG, Lakshmikantham, V: Fixed point theory in partially ordered metric spaces and applications. Nonlinear Anal. 65, 1379-1393 (2006). doi:10.1016/j.na.2005.10.017

2. Lakshmikantham, V, Ćirić, LjB: Coupled fixed point theorems for nonlinear contractions in partially ordered metric spaces. Nonlinear Anal. 70, 4341-4349 (2009). doi:10.1016/j.na.2008.09.020

3. Karapınar, E: Couple fixed point on cone metric spaces. Gazi Univ J Sci. 24(1):51-58 (2011)

4. Karapınar, E: Coupled fixed point theorems for nonlinear contractions in cone metric spaces. Comput Math Appl. 59(12):3656-3668 (2010). doi:10.1016/j.camwa.2010.03.062

5. Aydi, H, Mujahid, A, Postolache, M: Coupled coincidence points for hybrid pair of mappings via mixed monotone property. J Adv Math Studies. 5(1):118-126 (2012)

6. Aydi, H: Some coupled fixed point results on partial metric spaces. Int J Math Math Sci 2011, 11 (2011). Article ID 647091

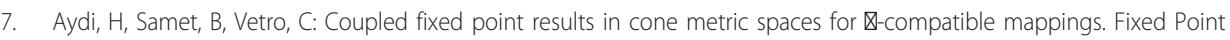
Theory Appl. 2011, 27 (2011). doi:10.1186/1687-1812-2011-27

8. Aydi, H, Damjanović, B, Samet, B, Shatanawi, W: Coupled fixed point theorems for nonlinear contractions in partially ordered G-metric spaces. Math Comput Model. 54, 2443-2450 (2011). doi:10.1016/j.mcm.2011.05.059

9. Aydi, H, Shatanawi, W, Postolache, M: Coupled fixed point results for $(\psi, \varphi)$-weakly contractive mappings in ordered Gmetric spaces. Comput Math Appl. 63, 298-309 (2012). doi:10.1016/j.camwa.2011.11.022

10. Choudhury, BS, Metiya, N, Kundu, A: Coupled coincidence point theorems in ordered metric spaces. Ann Univ Ferrara. 57, 1-16 (2011). doi:10.1007/s11565-011-0117-5

11. Choudhury, BS, Kundu, A: A coupled coincidence point result in partially ordered metric spaces for compatible mappings. Nonlinear Anal. 73, 2524-2531 (2010). doi:10.1016/j.na.2010.06.025

12. Luong, NV, Thuan, NX: Coupled fixed points in partially ordered metric spaces and application. Nonlinear Anal. 74, 983-992 (2011). doi:10.1016/j.na.2010.09.055

13. Samet, B: Coupled fixed point theorems for a generalized MeirKeeler contraction in partially ordered metric spaces. Nonlinear Anal. 74(12):4508-4517 (2010)

14. Samet, B, Vetro, C: Coupled fixed point, f-invariant set and fixed point of N-order. Ann Funct Anal. 1(2):46-56 (2010)

15. Berinde, $\mathrm{V}$, Borcut, $\mathrm{M}$ : Tripled fixed point theorems for contractive type mappings in partially ordered metric spaces. Nonlinear Anal. 74(15):4889-4897 (2011). doi:10.1016/j.na.2011.03.032

doi:10.1186/1687-1812-2012-44

Cite this article as: Aydi et al:: Tripled coincidence point theorems for weak $\phi$-contractions in partially ordered

metric spaces. Fixed Point Theory and Applications 2012 2012:44. 